\title{
Continuous monitoring of urine output and hemodynamic disturbances improves early detection of acute kidney injury during first week of ICU stay
}

\author{
M Flechet ${ }^{*}$, F Güiza, M Schetz, P Wouters, I Vanhorebeek, J Gunst, G Van den Berghe, G Meyfroidt
}

From ESICM LIVES 2015

Berlin, Germany. 3-7 October 2015

\section{Introduction}

Acute Kidney Injury (AKI) is associated with increased morbidity and mortality in critically ill patients [1]. Early detection and treatment may improve outcome. Previously, we developed a logistic regression (LR) model for early detection of AKI based on routinely collected data available at baseline, ICU admission and at the end of the first day (LR_BAD1) [2]. Continuous monitoring parameters may provide additional predictive power, in particular, urine output and hemodynamic parameters, whose management influences kidney perfusion.

\section{Objectives}

To assess if adding continuous monitoring variables recorded during the first $24 \mathrm{~h}$ of ICU stay, to a model to predict AKI in the first week of ICU admission, can improve the predictive performance.

\section{Methods}

The model was built and validated in a subset of $1778 \mathrm{ICU}$ patients from the EPaNIC trial [3]. Patients with end-stage renal disease, those with AKI on the first day of ICU stay and those without available hemodynamic monitoring data during the first day were excluded. AKI was defined by the creatinine criteria from the KDIGO guidelines.

The LR_BAD1 model used only covariates selected at baseline, ICU admission and at the end of the first day. In the LR_BAD1+ model, we have added features extracted from hourly measures of urine and minute-byminute measures of heart frequency (HF) and mean arterial blood pressure (MABP). Moreover, the

KULeuven, Laboratory of Intensive Care Medicine, Leuven, Belgium cumulative dose of inotropes administered to each patient during the first $24 \mathrm{~h}$ of ICU stay was used as additional covariate. The predictive power was assessed by ROC, decision and calibration curves analysis using 300 bootstraps replicates.

\section{Results}

Baseline characteristics are reported in Table 1. Performance of the model is shown on Figure 1 and in Table 2. Performance of LR-BAD1 is slightly different than what was reported in [2] as here it is evaluated in a different population. As compared to the LR-BAD1 model, the LR$\mathrm{BAD} 1+$ model had better discrimination (Auroc $\mathrm{p}$-value $=$ 0.05 and discrimination slope p-value $<0.01$ ) while retaining good calibration and net benefit. Model performance increased the most with hemodynamics features. Highly predictive features included the MABP median and slope, the time the patient's MABP was outside the interval defined by the MABP mean +- 2 standard deviation, HF median and standard deviation, the total amount of urine and the number of urine measurements.

\section{Conclusions}

Early detection of AKI can be improved by routinely monitored information of urine and hemodynamics. Hence, AKI can be already predicted with high discrimination and good calibration, only by using routinely collected ICU data.

\section{Grant Acknowledgment}

GM receives funding from FWO (1846113N). GVdB receives long-term research financing via the Flemish government Methusalem-program. 
Table 1. Demographics - 1778 ICU patients

\begin{tabular}{ll}
\hline Age (years): median [IQR] & $65.50[54.55-74.50]$ \\
\hline Apache II: median [IQR] & $18.00[13.00-29.00]$ \\
\hline ICU length of stay (hours): median [IQR] & $69.00[35.00-151.00]$ \\
\hline Baseline serum creatinine (mg/dl): median [IQR] & $0.92[0.77-1.06]$ \\
\hline Type of admission: elective/emergency (\%) & $1155(64.96) / 623(35.04)$ \\
\hline Diagnostic group: cardiac/transplant/non cardiac surgery and trauma-burns/medical-others (\%) & $1186(66.70) / 131(7.37) / 385(21.65) / 76(4.27)$ \\
\hline Male gender: $\mathrm{n}(\%)$ & $1123(63.16)$ \\
\hline Sepsis on ICU admission: $\mathrm{n}(\%)$ & $285(16.03)$ \\
\hline Diabetes: $\mathrm{n}(\%)$ & $274(15.41)$ \\
\hline Incidence of AKI within first week: $\mathrm{n}(\%)$ & $241(13.55)$ \\
\hline
\end{tabular}
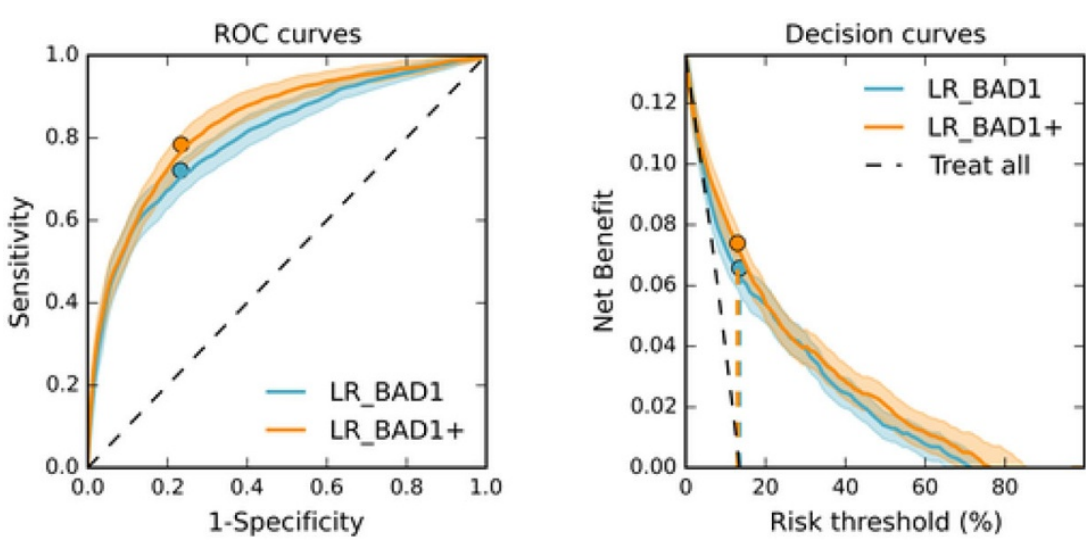

Figure 1 ROC and decision curves of LR_BAD1 and LR_BAD1+.

Table 2. Statistics of LR BAD1 and LR BAD1+

\begin{tabular}{llll}
\hline & LR_BAD1 & LR_BAD1+ & p-value \\
\hline Auroc & $0.80+-0.01$ & $0.84+-0.01$ & 0.05 \\
\hline Net benefit & $0.07+-0.01$ & $0.08+-0.01$ & 0.20 \\
\hline Calibration slope & $0.87+0.09$ & $0.88+-0.08$ & 0.45 \\
\hline Calibration-in-the-large & $0.00+-0.01$ & $0.00+-0.01$ & 0.47 \\
\hline Discrimination slope & $0.22+-0.01$ & $0.27+-0.02$ & $<0.01$ \\
\hline
\end{tabular}

Published: 1 October 2015

\section{References}

1. De Geus H, et al: Am J Respir Crit Care Med 2011.

2. Flechet $\mathrm{M}$, et al: Crit Care 2015.

3. Casaer $\mathrm{M}$, et al: $\mathrm{N}$ Engl J Med 2011.

\section{doi:10.1186/2197-425X-3-S1-A13}

Cite this article as: Flechet et al: Continuous monitoring of urine output and hemodynamic disturbances improves early detection of acute kidney injury during first week of ICU stay. Intensive Care Medicine Experimental 2015 3(Suppl 1):A13.

\section{Submit your manuscript to a SpringerOpen ${ }^{\circ}$ journal and benefit from:}

- Convenient online submission

- Rigorous peer review

- Immediate publication on acceptance

- Open access: articles freely available online

- High visibility within the field

- Retaining the copyright to your article

Submit your next manuscript at $>$ springeropen.com 